\title{
An Experimental Study to Determine the Life Time of Naturally Aged Transformer Oil
}

\author{
O. E.GOUdA*, G. M.AMER**, AND A. H. IBRAHIM*** \\ * Electrical and Machine Dept., Cairo University, Egypt, \\ ossama_241@hotmail.com \\ **Electrical Dept., Benha Higher Institute of Tech., Egypt, \\ dr.ghada11@hotmail.com \\ *** Coke and Chemicals, Helwan, Egypt
}

\begin{abstract}
Several efforts have been made over the past years to study the electrical, physical and chemicals properties of insulating oils. Among those efforts there is a property of natural aged oils (real oil samples corresponding to the scale of industrial transformers). This is investigated in this paper to determine the lifetime of naturally aged oil with different applied electric field and different shapes. This paper presents an experimental work to study the lifetime of transformer oil as a function of conduction current. In this paper, the electrification current in the tested oil is measured for different temperatures. Finally, tests have been carried out on oil samples under testing with different services period to determine the relation between breakdown voltage and the oil lifetime under uniform and nonuniform fields.
\end{abstract}

\section{Introduction}

Breakdown in transformer oil has been for years the subject of many investigations. It is well known that the electric strength of the aged transformer oil is greatly influenced by a large number of factors extraneous to the fresh oil state. Therefore, it is impossible to speak about intrinsic breakdown strength of a liquid dielectric. It is noticed that aging of transformer oil plays an important role in the breakdown mechanism of transformer oil ${ }^{[1-3]}$. Aging of the 
transformer oil causes some of the electrons to gain more energy from the field than they lose to the molecules in non-ionizing collisions. These electrons are accelerated until they gain sufficient energy, to ionize the transformer oil molecules, and thus build up an electron avalanche ${ }^{[4]}$. The aging process is one of most important factors influencing the change of transformer oil. It was shown in reference ${ }^{[5]}$ that aging causes not only quantitative but also qualitative changes in oil properties. The aging process occurring during the service of a transformer may change the electric properties of the oil and may damage the insulation system ${ }^{[6-7]}$. The purpose of the work reported here has been to determine the lifetime of naturally aged transformer oil. This is done by recording the conduction current of naturally aged transformer oil under different applied voltages and estimating the lifetime equation to be able to determine the unknown lifetime of oils if the conduction currents as a function of voltages are known.

\section{Experimental Techniques}

The present investigation was carried out on fresh and naturally aged oil of 5 to 32 years; the conduction current is measured under different applied voltage. This current is measured with micro ammeter capable of measuring low currents as low as possible. Shielding of the micro ammeter cables and measuring tank is essential in measuring such small currents and to avoid external interference.

\subsection{Oil Transformer Samples Used in Testing}

Five aged transformer oil samples and new one are tested to study the performance of conduction current under testing voltage as a function of the oil lifetime. Aged oil is sampled from an outdoor 100MVA, 115/66 kV transformers, with a maximum oil temperature rise of $55^{\circ} \mathrm{C}$. These units operate in Coke Company.

This is a refinery area located in south of Helwan. Ambient temperature varies from $10-45^{\circ} \mathrm{C}$, and relative humidity ranges from 40 to $60 \%$.

\subsection{Oil Tester Used in Testing}

$100 \mathrm{kV}$ oil tester with accuracy of measuring within $\pm 2.5 \%$ is used in this work. The applied voltage was obtained from oil tester complying with IEC and the voltage was increased practically continuously up to the puncture of the oil sample, the rate of rise was constant and equal to $3 \mathrm{kV} / \mathrm{sec}$ automatically by motor drive. The pointer of the instrument is retained for some time so that the reading is facilitated and the conduction current was measured by a sensitive 
micro ammeter with an accuracy of $\pm 1 \%$. The oil was allowed to rest at least 2 minutes after the test cell was filled with oil cell. Due to the low repeatability of each test the result is stated as the average of five breakdown voltage for a given configuration tests. The test cell and electrodes are cleaned from moisture and dirty oils. This is achieved by pouring a little of sample oil over the electrodes, swilling it round the cell and pouring it away. This operation is repeated twice before the oil sample is finally poured in for testing. Between tests of different samples, the oil was poured away and the cell was left in an inverted position to exclude dirt and moisture. The oil under test is poured in to the clean cell without splashing, until the oil level is $20 \mathrm{~mm}$ above the electrodes ${ }^{[8]}$. It is then left standing for 20 minutes to allow air bubbles to escape by a small electric fan immersed in the oil cell. . Screen breakdowns are taken with five minutes separation between each, the first measurement is rejected and the other six are used to calculate the average breakdown voltage. The test was carried out at room temperature.

\section{Results and Discussion}

\subsection{Conduction Current of Naturally Aged Oil}

The tested oil is fresh and aged for 5 to 32 years. The conduction current is measured under uniform and non-uniform fields. Figure (1) presents the variation of conduction current as a function of applied voltage. In general, the results show that the conduction current increases with increasing the applied voltage. The family of curves given in figure (1) is represented by the equation:

$$
i=\left(a+b c+e^{-c v}-e^{-d v}\right) /(d-c)
$$

Where $\mathrm{a}, \mathrm{b}, \mathrm{c}$ and $\mathrm{d}$ are constants depend on the electrode configuration and oil type. These constants are calculated by fitting the curves given in figure (1) and they are tabulated in Table (1). The statistics of this equation is shown in Table (1). From this table it is found that fit standard errors varied from 0.137976 in case of sphere- rode ((-) ve.) to 0.31806738 in case of plane- rod ((-) ve.)

The conduction current in ( $\mathrm{uA})$ is measured also as a function of applied voltage $(\mathrm{kV})$ for different service periods of the aged oils. The relations between the applied voltage and conduction current are plotted in figures $(2,3$, 4, 5 and 6) for different aged oils. These plots are depending on the degree of oil aging. The oil of lifetime of 5 years and 10 years in service has proved to generate positive conduction currents. Those currents are, however, higher than of fresh oil. 


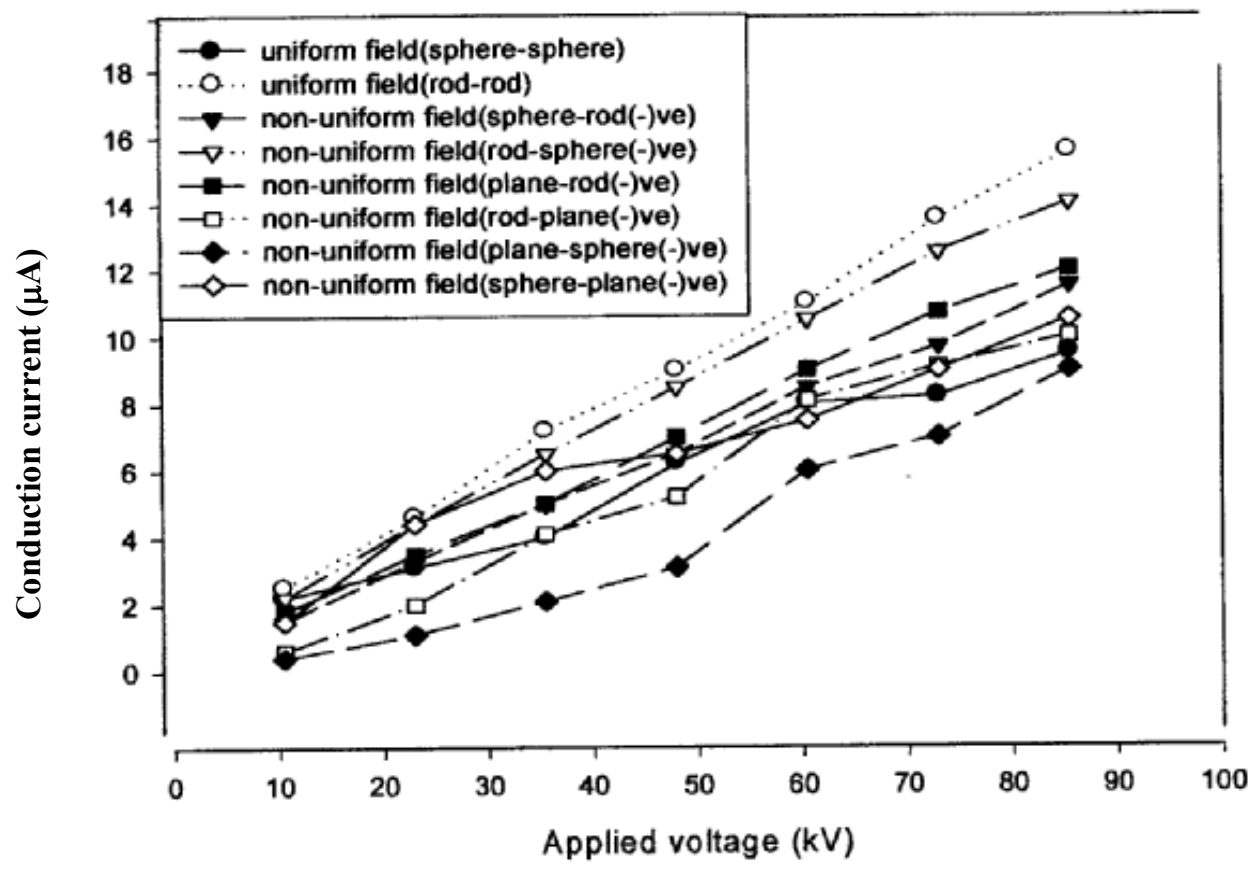

Fig. 1: The relation between conduction current and applied voltage for various electrode configurations.

Table 1: Constants of oil samples for various electrode configurations.

\begin{tabular}{|l|c|c|c|c|c|}
\hline \multicolumn{1}{|c|}{$\begin{array}{c}\text { Electrode } \\
\text { configuration }\end{array}$} & $\begin{array}{c}\text { Fit std. } \\
\text { errs }\end{array}$ & a & b & C & d \\
\hline Sphere-sphere & 0.28816293 & 0.831951 & 40.399163 & 0.037701155 & .02222 \\
\hline Rod-rod & 0.20641168 & -1.906940 & 31.894796 & 0.059796047 & 0.00980 \\
\hline Sphere-rod ((-ve.) & 0.13797605 & -1.815489 & 22.527766 & 0.059242144 & 0.0033 \\
\hline Rod-sphere ((- ve.) & 0.20480861 & 0.949019 & 31.734363 & 0.03855719 & 0.0106 \\
\hline Plane-rod ((-) ve.) & 0.31806738 & 1.682415 & 24.840681 & 0.07616761 & 0.0005 \\
\hline Rod-plane ((-) ve.) & 0.22596082 & 0.605910 & 21.445885 & 0.052362665 & $\mathrm{e}^{-12}$ \\
\hline Plane-sphere ((-) ve.) & 0.23965502 & 0.004256 & 26.679157 & 0.053472738 & 0.00254 \\
\hline Sphere-plane ((-) ve.) & 0.19258253 & 1.391387 & 35.778644 & 0.040336624 & 0.0199 \\
\hline
\end{tabular}




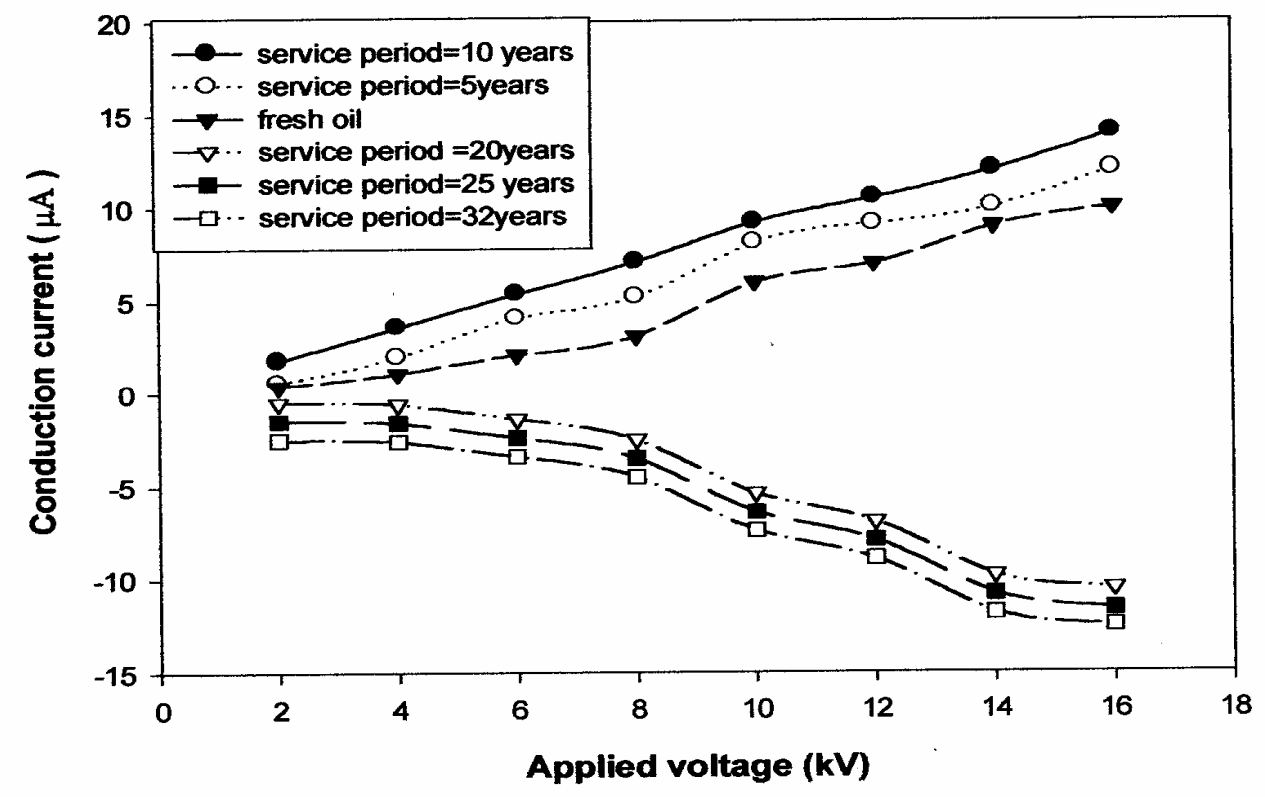

Fig. 2: The relation between conduction current and applied voltage for aged oil in case of uniform field (sphere-sphere).

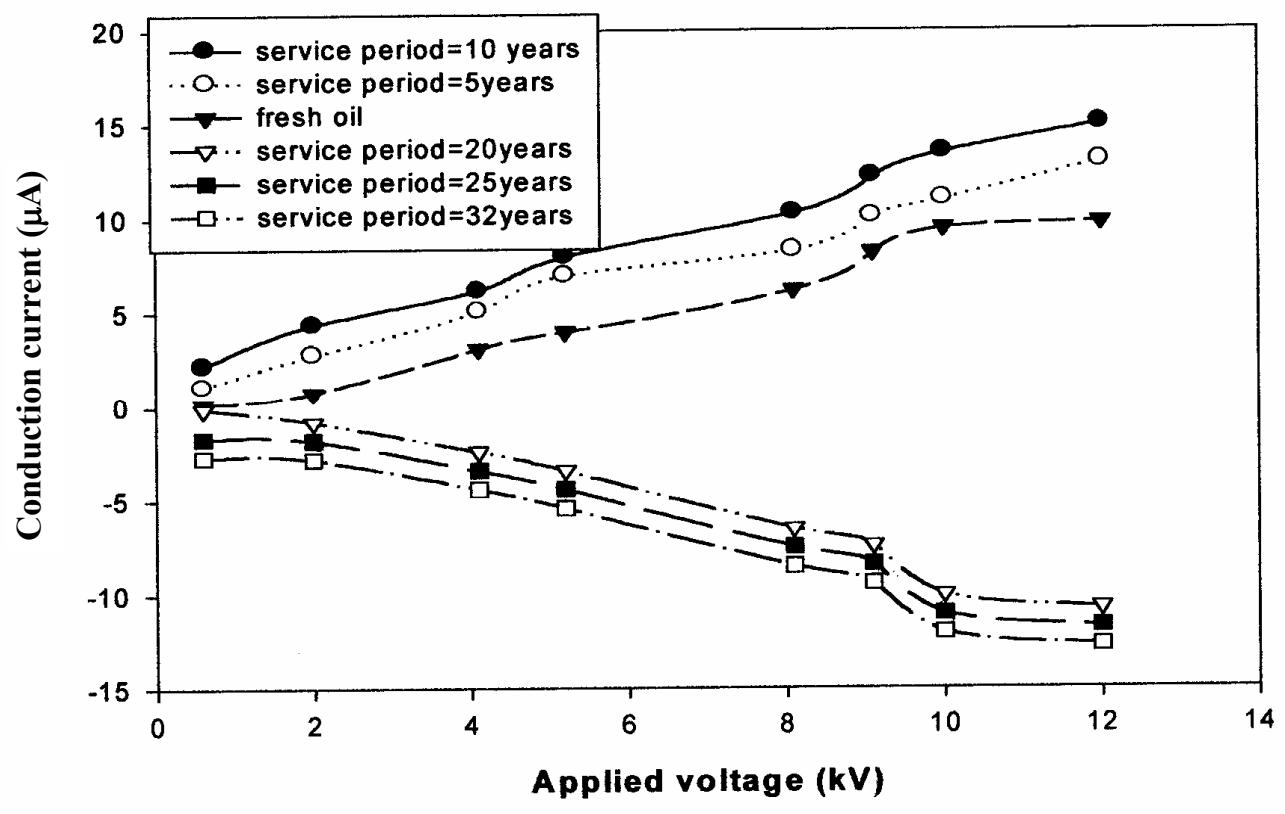

Fig. 3: The relation between conduction current and applied voltage for aged oil under uniform field (rod-rod). 


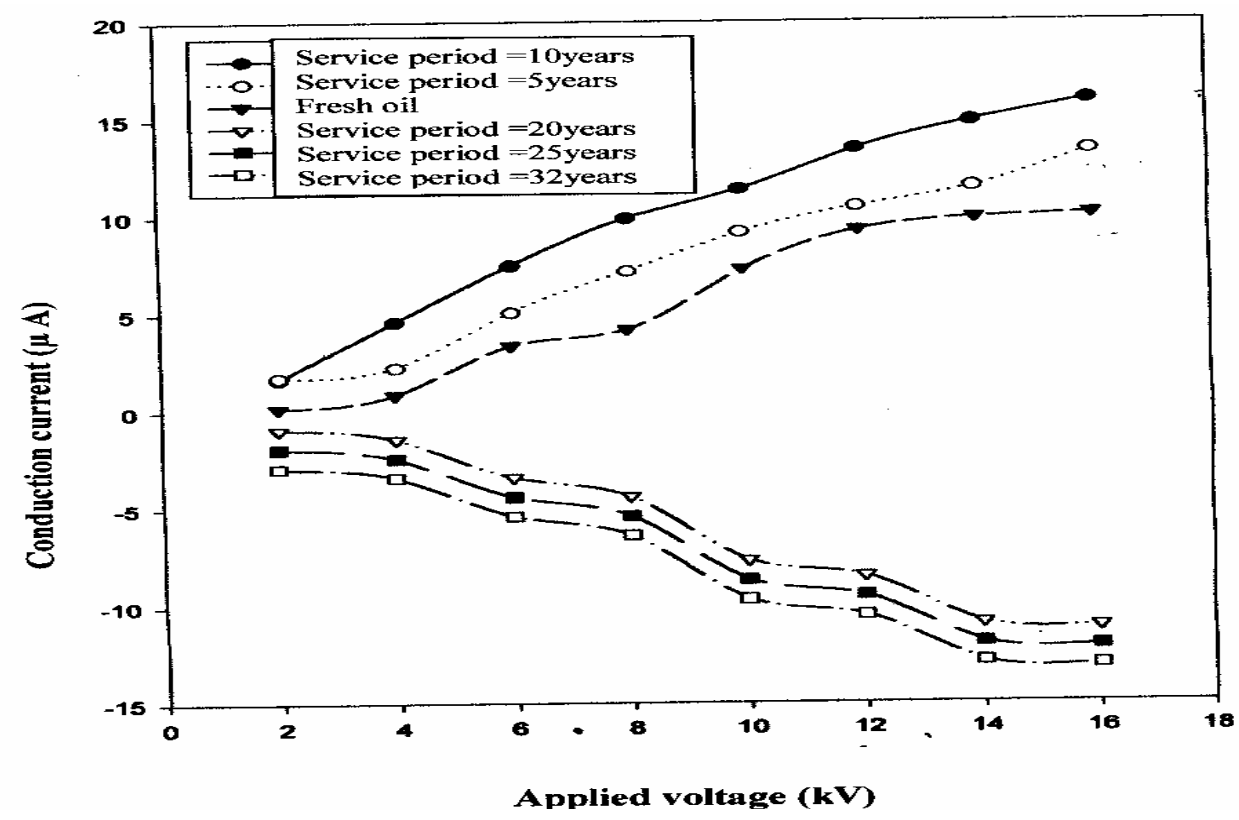

Fig. 4: The relation between conduction current and applied voltage for aged oil in case of non-uniform Held (Sphere-rod (-) ve).

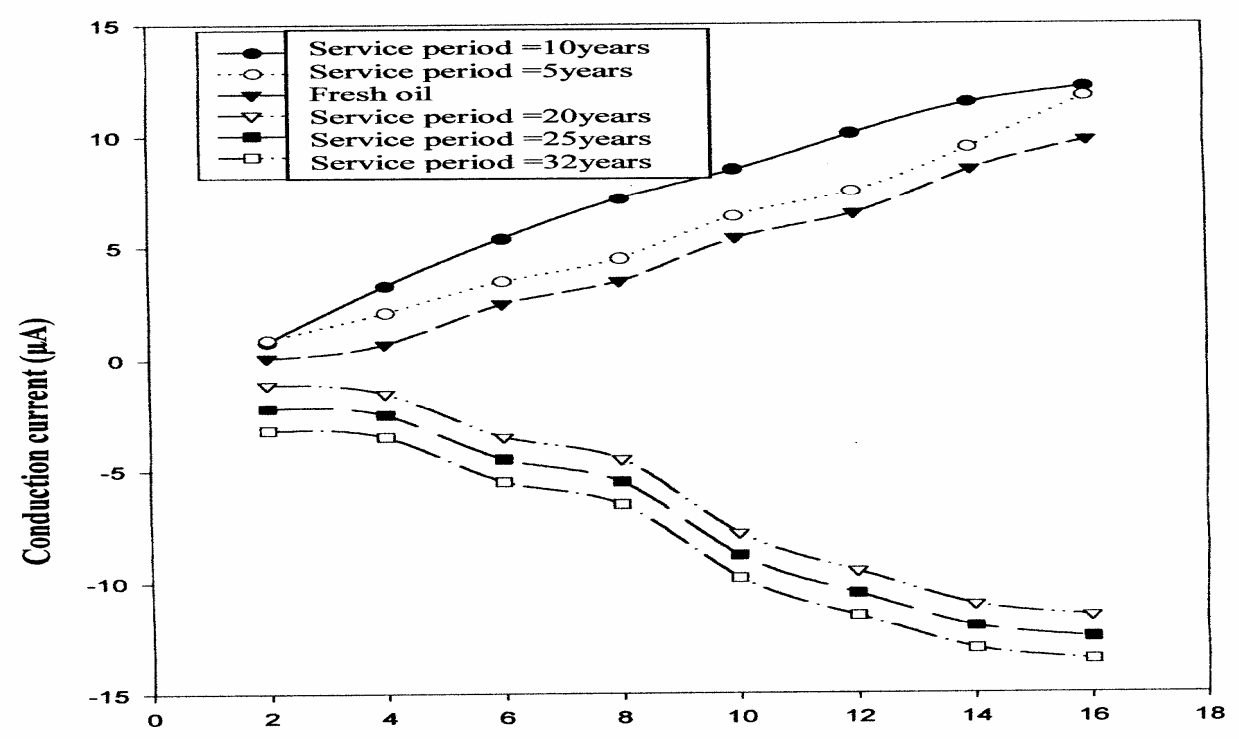

Applied voltage (kV)

Fig. 5: The relation between conduction current and applied voltage for aged oil in case of non-uniform field (rod-sphere (-) ve)). 


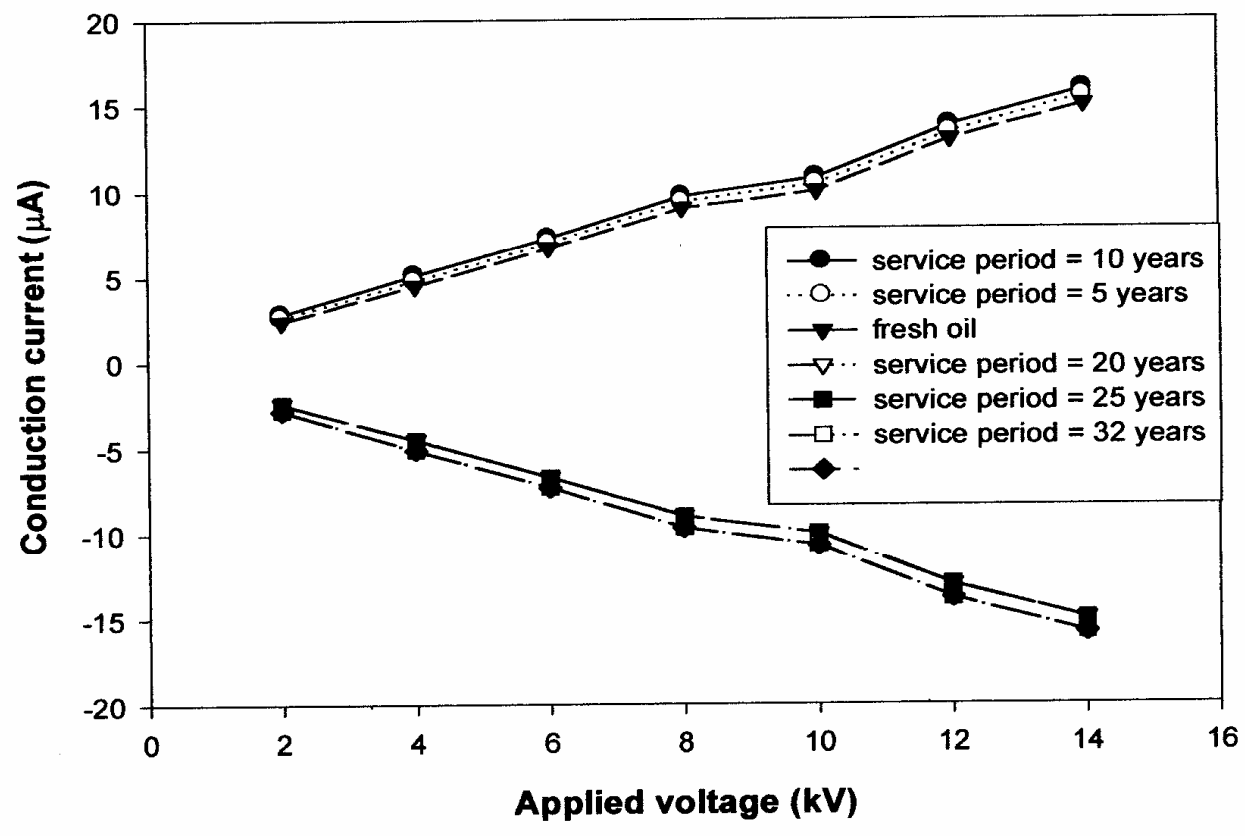

Fig. 6: The relation between conduction current and applied voltage for aged oil in case of non-uniform field (Rod- sphere (-) ve.).

The oil samples of lifetime of 20, 25 and 32 years in service has proved to generate negative conduction currents and the slopes of the curves increase with the degree of oil aging. This can be explained as the increase of the degree of oil aging causes transformer oil to contain some impurity particles, which are present gradually, and particles grow in size. Silent discharges and concentrated conduction currents help the formation of water, resins, and acids and grow of hydrogen. Arcs discharges and intensive localized heating of the liquid produce particles of carbon, wax and gases such as carbon monoxide, carbon dioxide, acetylene and the acidic products due to oxidation and discharges attack the solid process occurring once the electron has been injected into the transformer oil, it gains energy from the applied field, it is assumed that at sufficiently high fields some of the electrons will gain more energy from the field than they lose to the molecules. These electrons are accelerated until they gain sufficient energy, to ionize the oil molecules, and thus build up an electron avalanche generating negative leakage current.

The results of the tests indicate that an absolute value and sign of the leakage current depends on the degree of oil aging. This may be explained that when oil samples have a long life time at least more than ten years the accumulation of contamination $+v e$ ions on the $-v e$ electrode and also the 
accumulation of $-\mathrm{ve}$ ions on the $+\mathrm{ve}$ electrode lead to change the direction of conduction current. The relation between the conduction current and lifetime of the aged oil at constant applied voltage is given in figure (7). The conduction currents of aged oil having lifetime between 10 years and 20 years are not measured because we have not samples having this life time but of course the conduction current in this period is not almost zero under different applied voltage This family of curves could be expressed by equation (2) at constant applied voltages.

$$
L=y+(a / i)+\left(b / i^{2}\right)+\left(c / i^{3}\right)
$$

Where:

$L$ the lifetime

$i$ the conduction current in (uA)

$y, a, b$ and $c$ are constants depend on the applied voltage. These constants are tabulated in Table (2).

The lifetime of the aged oil could be determined from equation (2) when testing the aged oil under known voltage and recording the conduction current.

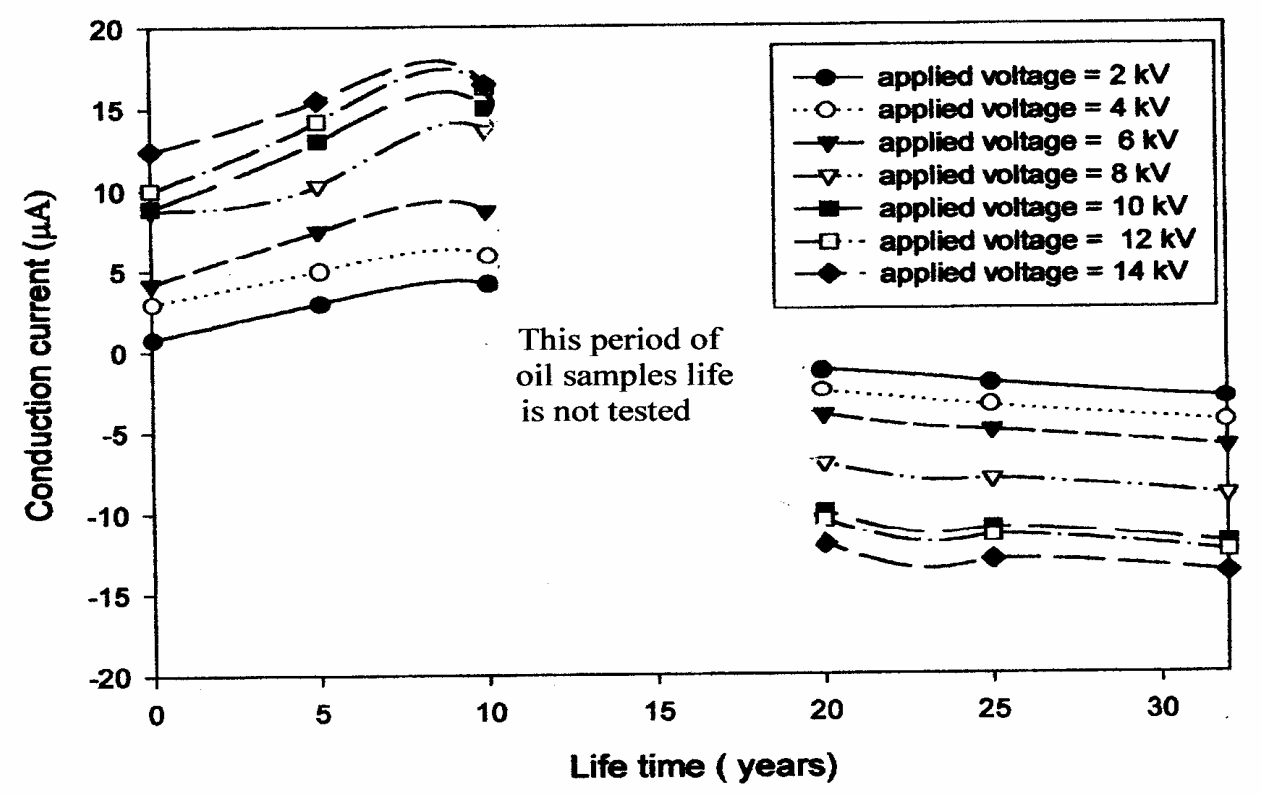

Fig.7: The relation between conduction current and lifetime for various applied voltage. 
Table 2: Aging constants for transformer oil under various applied voltage.

\begin{tabular}{|c|c|c|c|c|}
\hline $\begin{array}{l}\text { Applied } \\
\text { Voltage (kV) }\end{array}$ & $\mathbf{y}$ & $\mathbf{a}$ & $\mathbf{b}$ & $\mathbf{c}$ \\
\hline 2 & $-6.335 \mathrm{e}^{\mathrm{o}}$ & $1.44 \mathrm{e}^{2}$ & $-8.545 \mathrm{e}^{2}$ & $1.833 \mathrm{e}^{3}$ \\
\hline 4 & $-1.035 \mathrm{e}^{\mathrm{o}}$ & $2.407 \mathrm{e}^{2}$ & $-1.521 \mathrm{e}^{3}$ & $3.509 \mathrm{e}^{3}$ \\
\hline 6 & $-1.343 \mathrm{e}^{\mathrm{o}}$ & $2.94 \mathrm{e}^{2}$ & $-1.647 \mathrm{e}^{3}$ & $3.508 \mathrm{e}^{3}$ \\
\hline 8 & $-1.992 \mathrm{e}^{0}$ & $4.136 \mathrm{e}^{2}$ & $-2.02 \mathrm{Ie}^{3}$ & $3.552 \mathrm{e}^{3}$ \\
\hline 10 & $3.010 \mathrm{e}^{\mathrm{o}}$ & $6.997 \mathrm{e}^{2}$ & $-4.508 \mathrm{e}^{3}$ & $1.044 \mathrm{e}^{3}$ \\
\hline 12 & $-3.074 \mathrm{e}^{\mathrm{o}}$ & $7.003 \mathrm{e}^{2}$ & $-4.338 \mathrm{e}^{3}$ & $9.810 \mathrm{e}^{3}$ \\
\hline 14 & $-3.58 \mathrm{e}^{0}$ & $8.482 \mathrm{e}^{2}$ & $-5.693 \mathrm{e}^{3}$ & $1.368 \mathrm{e}^{3}$ \\
\hline
\end{tabular}

\subsection{Static Electrification of Naturally Aged Oil}

In this paper the measurement of the potential of electric charges and conduction current in the oil, or measurement of current leakage from the solid phase, is the idea on which the spinning disc measuring system is based. The dependence of current on the rotary speed for different temperatures (fresh oil) is shown in figure (8). It can be seen that the current increases with temperature increase because of rupture of the charged double layer on the interface of the solid and liquid phase. The flow of the liquid carries a part of the electric charge of the double layer and generates free electric charges increasing with temperature, decrease the fluid viscosity. The liquid (transformer oil) in the solid phase arrangement is displaced, when formally approached, the problem of disrupting the double layer of charge may also occur during the displacement of the solid phase. It is noticed that, the higher the speed of the oil, the higher the conduction current, because of increase shear stress ${ }^{[6]}$.

The relation between conduction current and the electrification speed for different temperatures is shown in figure (9), for the oil had aged naturally of 5 years, the conduction current in pA versus the motor speed in r.p.m. These characteristics show great similarity in the shape of the curves with charge in the service period, but the value of conduction current decreases with the increase of the service period. Similar investigations of the aged samples are carried out at the same electrification speed; the results are presented in figures (10) to (13). From these figures, it is noticed that the electrification currents as a function of lifetime are identical for different life times of oil and for the same type of oil used. The obtained results are in agreement with that obtained by reference ${ }^{[7]}$. From figures (8-13), it noticed the rate of increase of conduction current versus motor speed is not constant and the conduction current decreases with the increasing of the tested oil lifetime. As example at 
500-r.p.m motor speed the conduction current is about $800 \mathrm{PA}$ at $80{ }^{\circ} \mathrm{C}$ (figure 8). This value reached to about $700 \mathrm{PA}$ when the tested oil has 5 years in service (figure 9) and reached to about 650PA in case of testing 10 years in service aged oil (figure (10). When testing oil samples 20 years in service negative conduction current is presented and it increases with increasing the motor speed as given in figure (12). Similar results are obtained when testing samples oil 25 years, and 32 years in service.

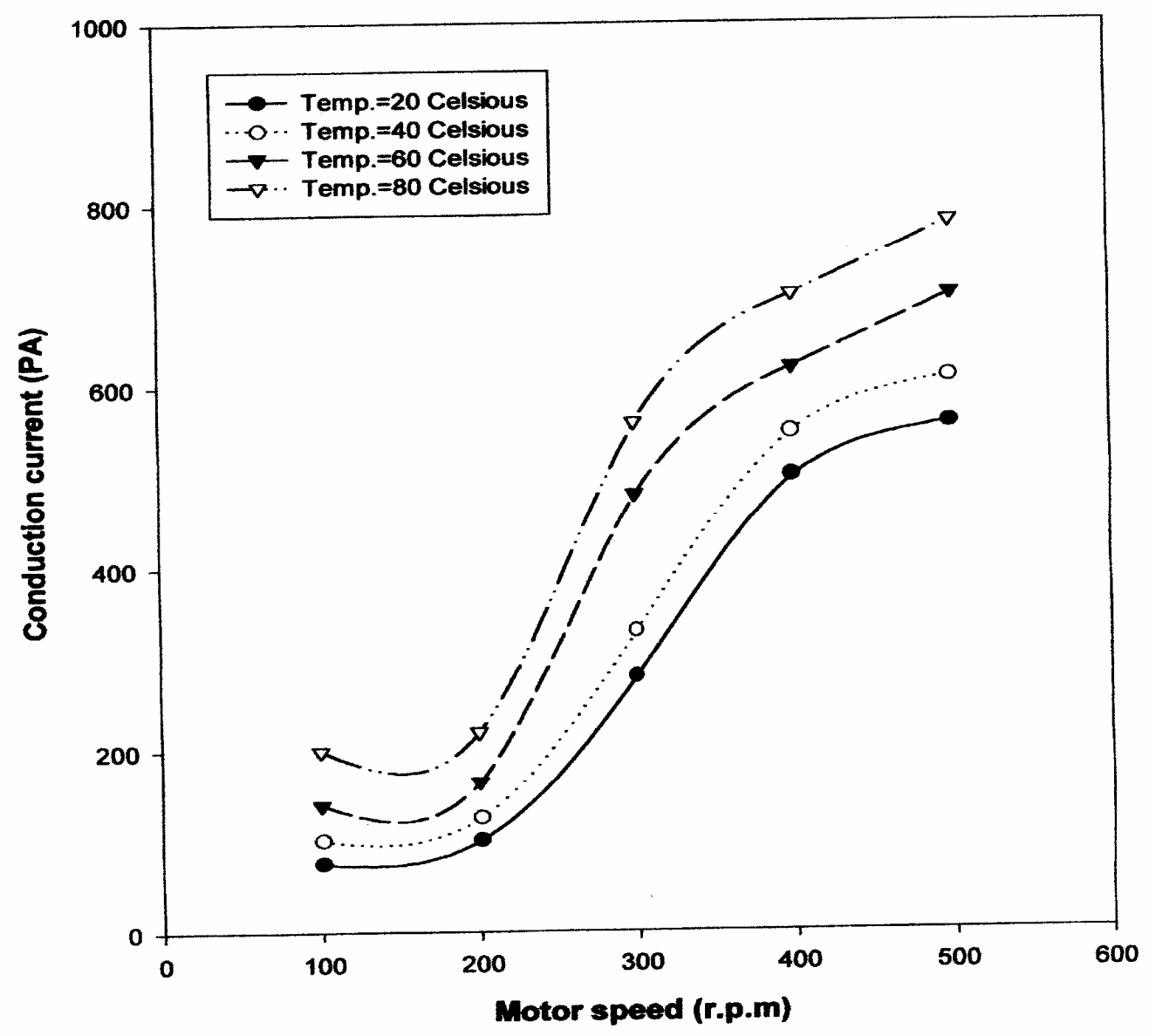

Fig. 8: The relation between the electrification speed and the conduction current for various temperatures (fresh oil). 


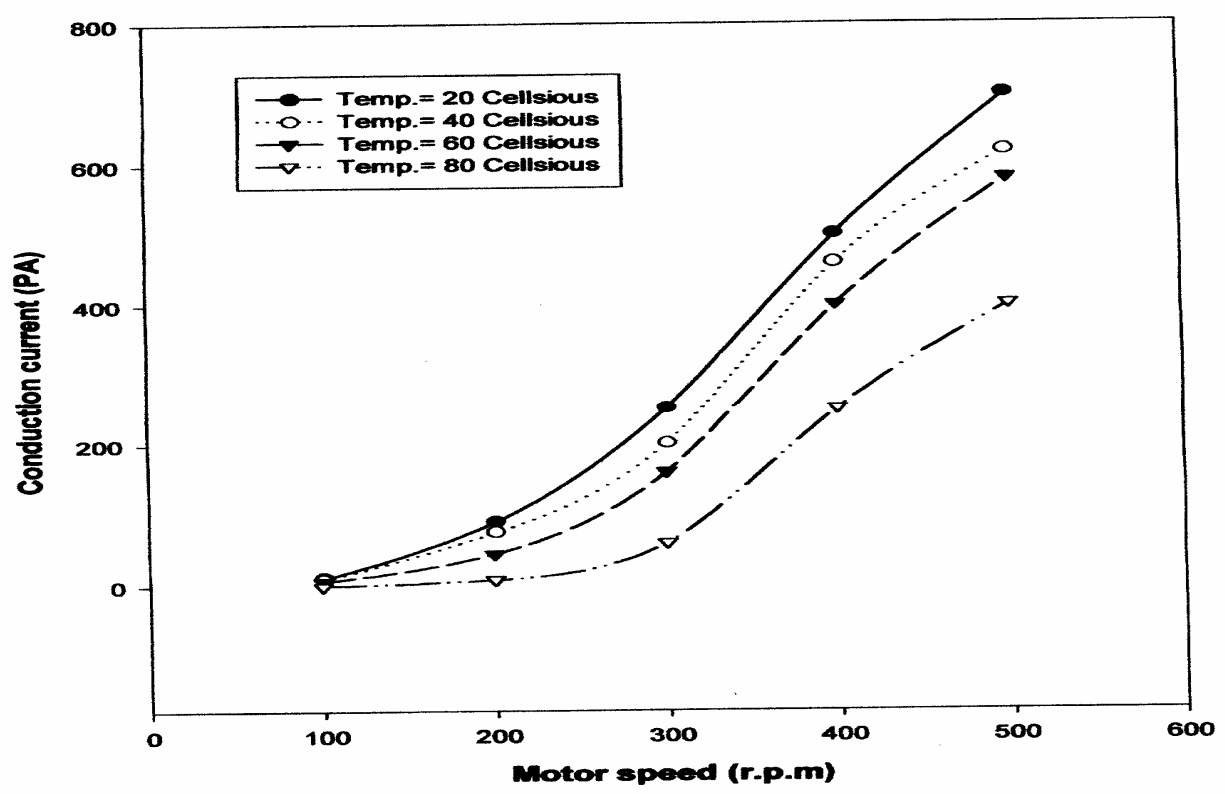

Fig. 9: The relation between the electrification speed and the conduction current for various temperatures (Aged oil, 5 years in service).

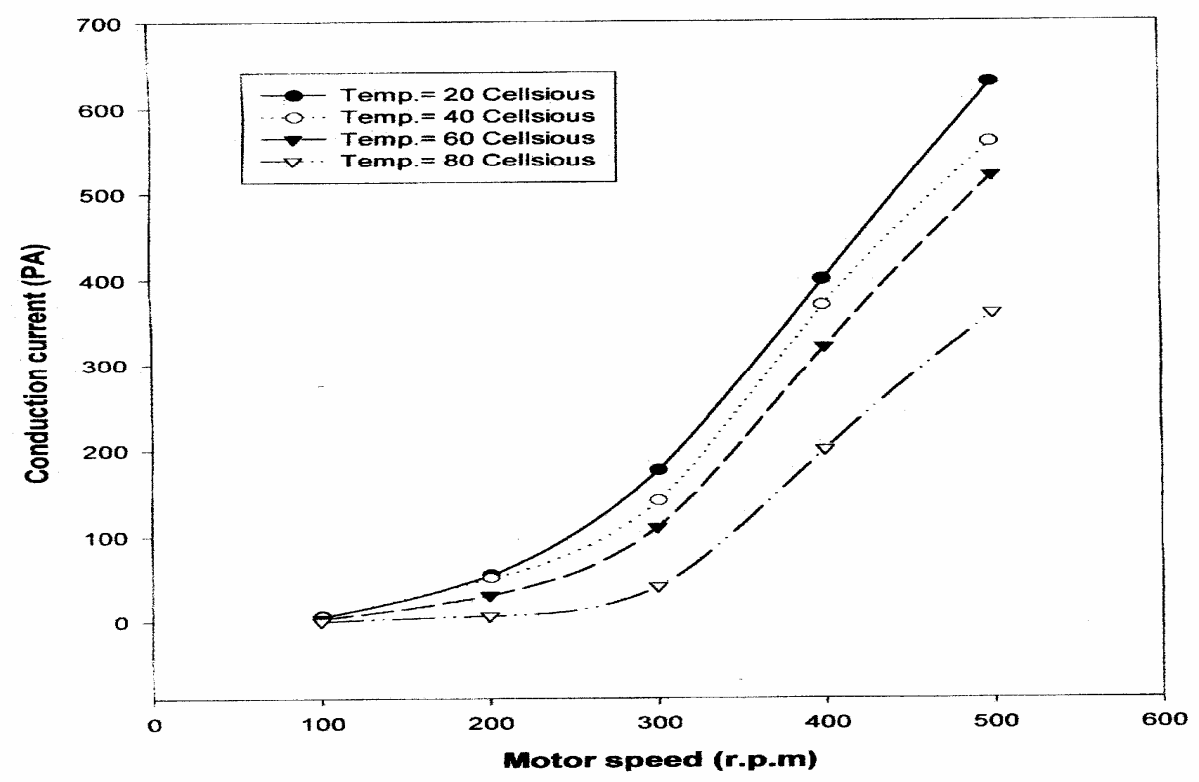

Fig. 10: The relation between conduction current and the electrification speed for various temperatures (Aged oil, 10 years in service). 


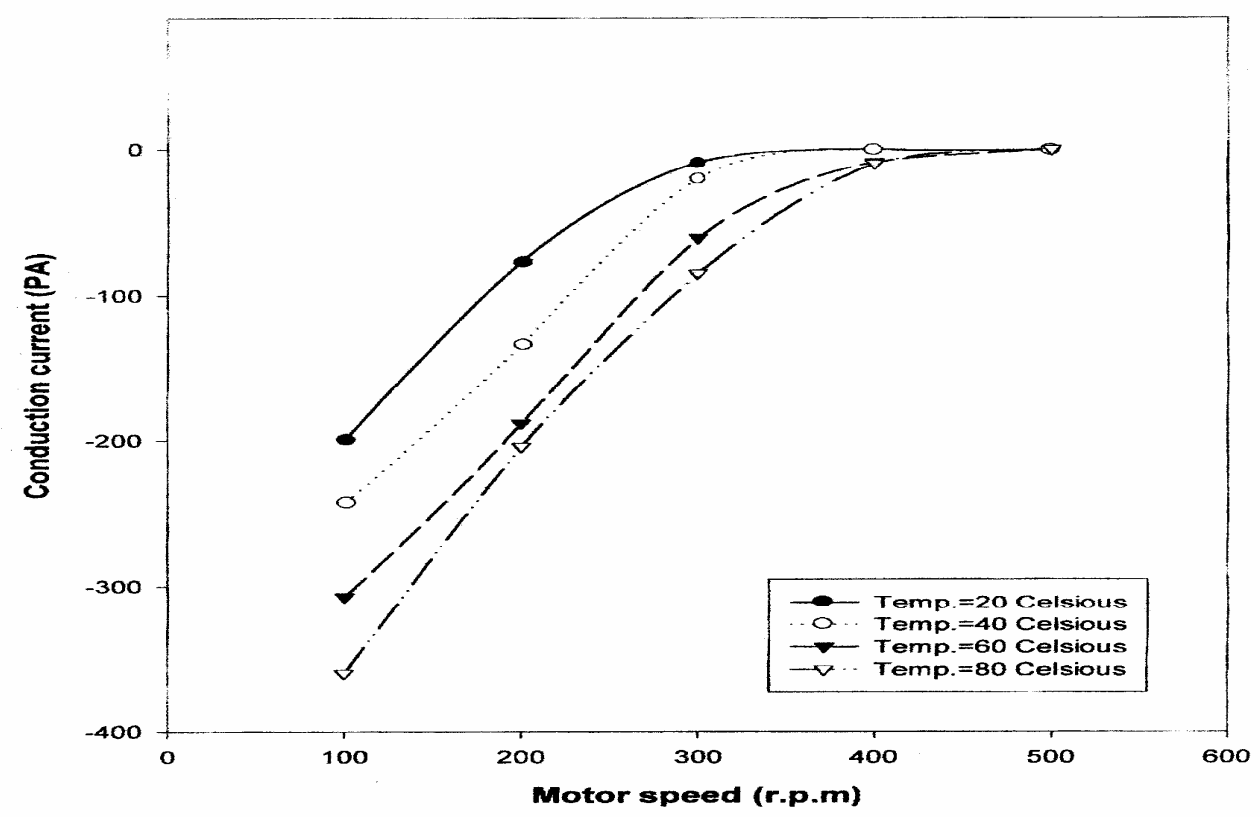

Fig.11: The relation between conduction current and the electrification speed for various temperatures (Aged oil, 20 years in service).

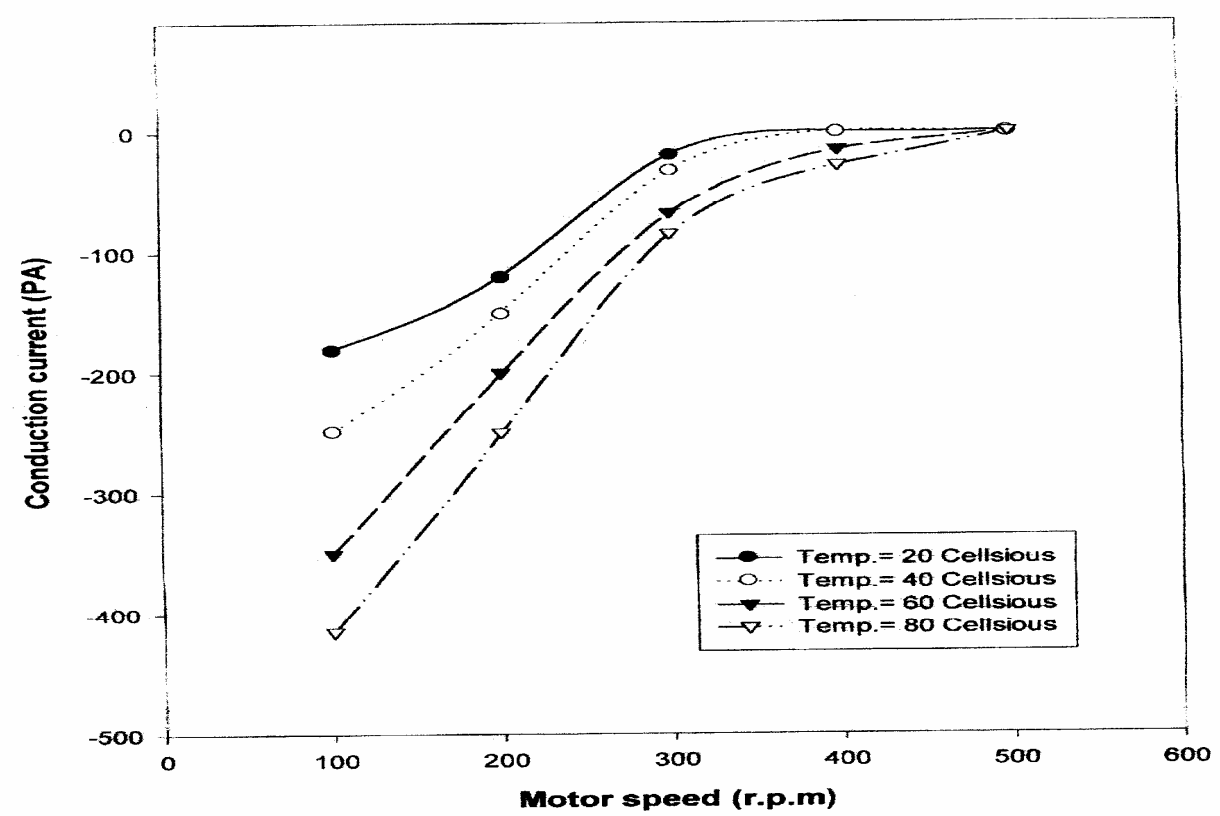

Fig.12: The relation between conduction current and the electrification speed for various temperatures (Aged oil, 25 years in service). 


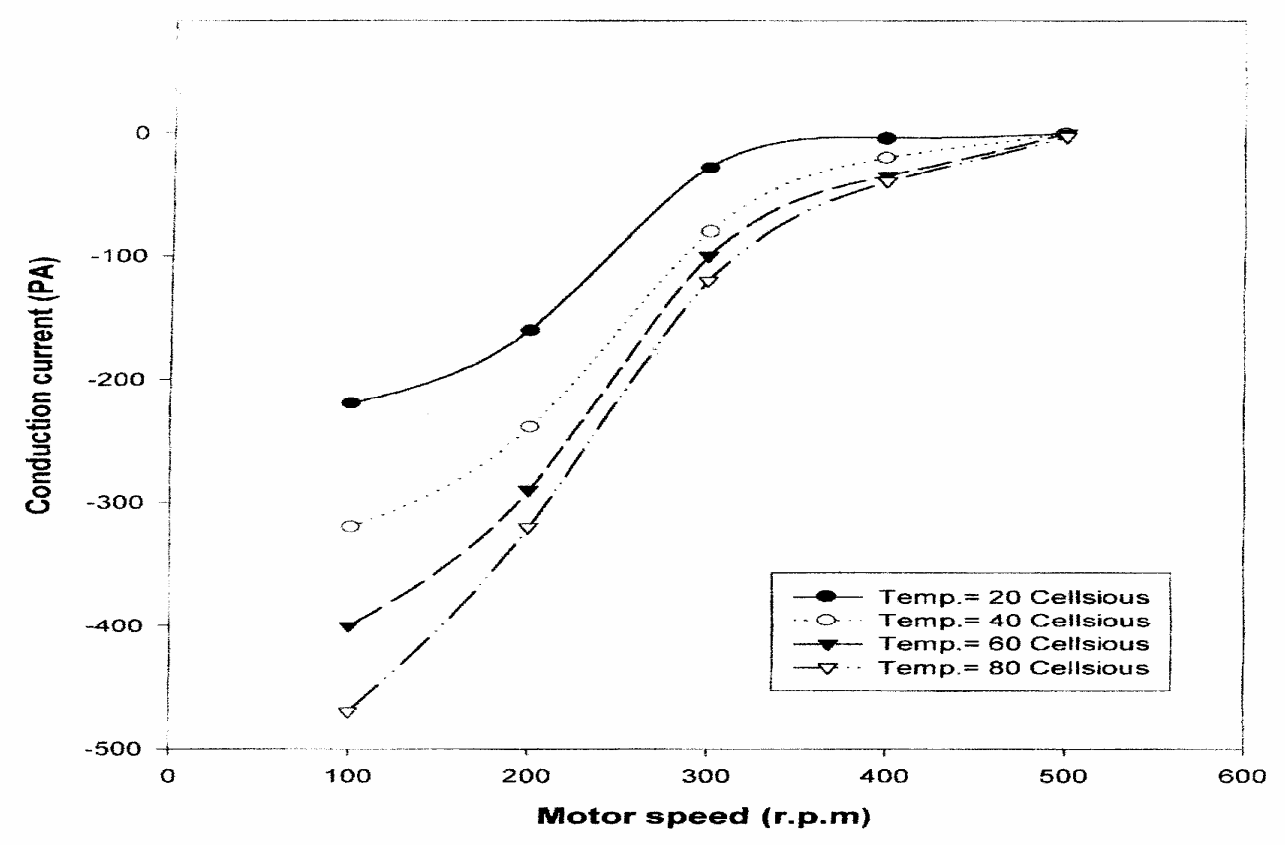

Fig.13: The relation between conduction current and the electrification speed for various temperatures (Aged oil, 32 years in service)

\subsection{Breakdown Voltage of Naturally Aged Transformer Oil under Uniform and Non-Uniform Fields}

Tests have been carried out on six samples of mineral transformer oil with diverse degrees of aging with different services period. International experience shows that the large power transformers can have service in excess of 50 years. There are a variety of chemical, electrical and physical conditions monitoring techniques, which can apply to identify the onset of unreliability as the end life ${ }^{[9]}$.

Consider the breakdown voltage in $(\mathrm{kV}$ 's) for the gap of standard electrode shape under uniform (sphere - sphere) and non - uniform (point - sphere) fields. The average and standard deviation B.D.V values, for samples of different service periods are presented. The method of standard deviation calculations is given by sigma plot 2000 (standard program works under windows). Figure (14) presents the relation between breakdown voltage of transformer oil and tests number in case of uniform field (sphere-sphere), non- uniform field (point-sphere) and uniform field after filtration. The obtained results are given 
in Table (3).From this table, it can be noticed that the breakdown voltage for uniform and non - uniform fields decreases with the increase of service period.

This may be explained as follows: While the insulating oil is in service some impurity, particles are present gradually and particles grow in size. Silent discharges and concentrated conduction current help the formation of water, resins, acids and grow of hydrogen. Arc discharges and intensive localized heating of the liquid produce particles of carbon, wax and gases such as carbon monoxide, carbon dioxide, acetylene and the acidic products due to oxidation and discharges attack the solid insulation, iron and copper immersed in the liquid, which lead to lower electric strength. The difference between the level of breakdown voltage of uniform and non-uniform fields is due to more carbonization and deterioration of the oil in case of non - uniform field. This is because of localized electric stress at sharp edges, which leads to break more oil molecules. The breakdown voltage is decreased from $42 \mathrm{kV}$ to $33.5 \mathrm{kV}$ in case of non - uniform field, between fresh oil and oil used for 32 years.

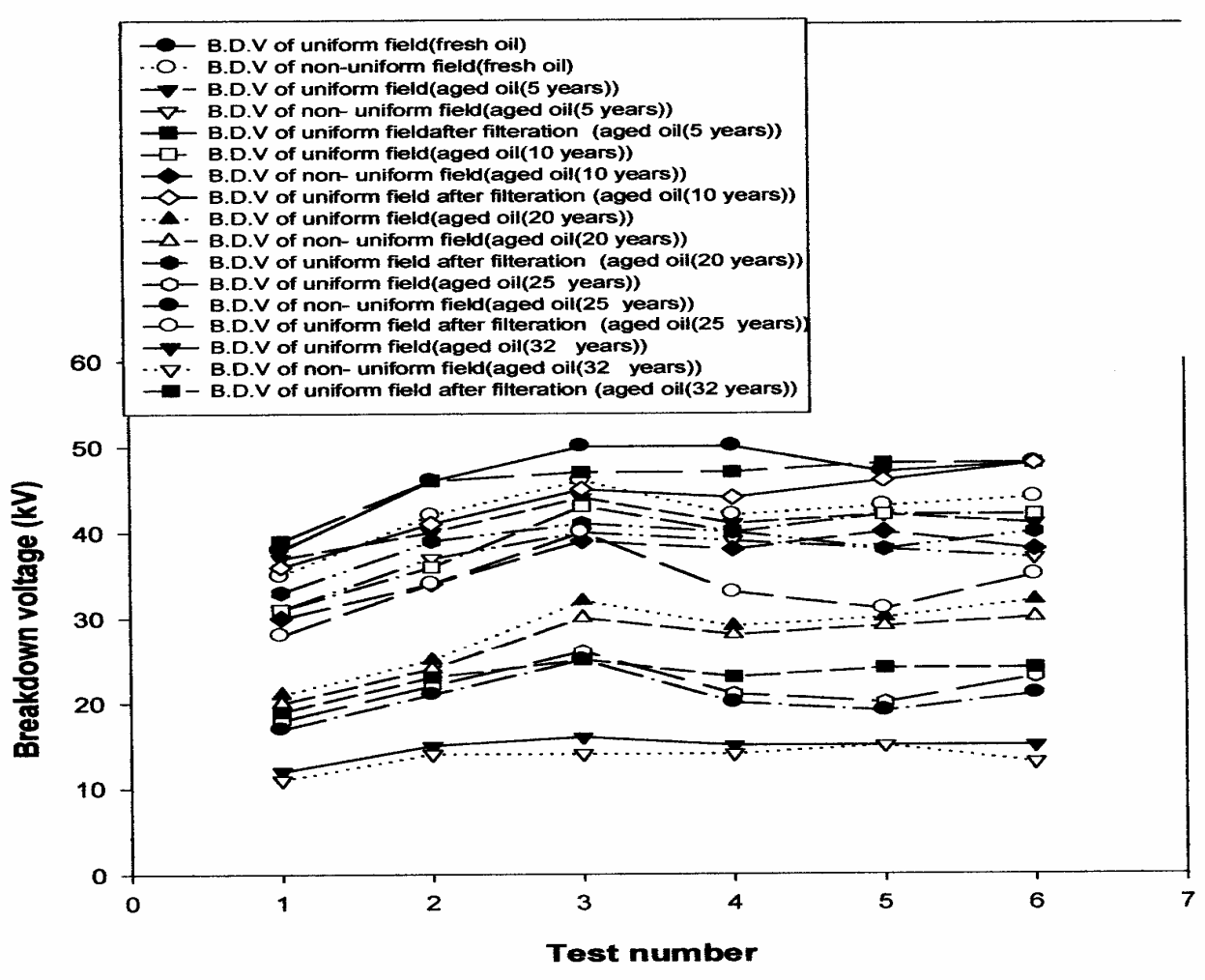

Fig. 14: The results of the breakdown voltage in $(\mathrm{kV})$ for samples of aged oil under uniform, non- uniform and after filtration for various service period 
Table 3: the obtained results of the BDV in $\mathrm{kV}$ for the different service period.

\begin{tabular}{|c|c|c|c|c|c|c|c|c|c|c|c|c|}
\hline $\begin{array}{c}\text { s.p. } \\
\text { s }\end{array}$ & \multicolumn{3}{|c|}{ Fresh } & \multicolumn{3}{|c|}{5} & \multicolumn{3}{c|}{10} & \multicolumn{3}{c|}{20} \\
\hline No & I & II & III & I & II & III & I & II & III & I & II & III \\
\hline 1 & 38 & 35 & 38 & 37 & 31 & 39 & 31 & 30 & 36 & 21 & 20 & 33 \\
\hline 2 & 46 & 42 & 46 & 40 & 37 & 49 & 36 & 34 & 41 & 25 & 24 & 39 \\
\hline 3 & 50 & 46 & 50 & 44 & 40 & 47 & 40 & 38 & 44 & 30 & 29 & 38 \\
\hline 4 & 47 & 42 & 47 & 41 & 39 & 47 & 40 & 38 & 44 & 29 & 28 & 40 \\
\hline 5 & 48 & 43 & 48 & 42 & 38 & 48 & 42 & 40 & 46 & 30 & 29 & 38 \\
\hline 6 & 49 & 44 & 49 & 41 & 37 & 48 & 42 & 38 & 48 & 32 & 30 & 40 \\
\hline Mean & 46.4 & 42 & 46.3 & 40.5 & 37 & 45.9 & 39 & 36.7 & 42.8 & 28.1 & 26.8 & 38.5 \\
\hline S.D & 4.37 & 3.7 & 4.32 & 3.66 & 3.16 & 3.52 & 4.69 & 3.88 & 3.67 & 4.35 & 4.02 & 2.88 \\
\hline S.E & 1.76 & 1.52 & 1.76 & 1.49 & 1.29 & 1.53 & 1.89 & 1.58 & 1.53 & 1.77 & 1.64 & 1.17 \\
\hline
\end{tabular}

\begin{tabular}{|c|c|c|c|c|c|c|}
\hline \multirow{2}{*}{ No } & \multicolumn{3}{|c|}{25} & \multicolumn{3}{c|}{30} \\
\cline { 2 - 7 } & I & II & III & I & II & III \\
\hline 1 & 18 & 17 & 28 & 12 & 11 & 19 \\
\hline 2 & 22 & 21 & 34 & 15 & 14 & 23 \\
\hline 3 & 20 & 19 & 31 & 16 & 14 & 25 \\
\hline 4 & 21 & 20 & 23 & 15 & 14 & 23 \\
\hline 5 & 20 & 19 & 31 & 15 & 15 & 24 \\
\hline 6 & 23 & 21 & 35 & 15 & 13 & 24 \\
\hline Mean & 21.7 & 20.5 & 33.5 & 14.6 & 33.5 & 23 \\
\hline S.D & 3.73 & 2.66 & 4.03 & 1.73 & 1.37 & 1.09 \\
\hline S.E & 1.11 & 1.64 & 0.55 & 0.56 & 0.56 & 0.85 \\
\hline
\end{tabular}

S.P.S Service period sample (year

I: BDV of uniform field (sphere-sphere)

II: BDV of non-uniform field (point-sphere)

III: BDV of uniform field after filtration.

S.D: Standard deviation.

S.E: Standard error.

Fig. (14) Presents the breakdown voltage of fresh oil in case of uniform and non-uniform fields versus the test number. When the number of tests increases the electric strength of the oil increases. This may be due to that the leakage current in the first test helps in vaporizing the water content in the oil and the other chemical particle is dissolved. Then it fluctuated between maximum voltage of $50 \mathrm{kV}$ and minimum value of $38 \mathrm{kV}$, the mean value of the breakdown for fresh oil is $43.7 \mathrm{kV}$, but in case of non-uniform field it is 42 $\mathrm{kV}$, i.e. breakdown voltage increases by $4 \%$ in case of uniform field. Fig. (14) Also, presents the breakdown voltage in case of uniform, nonuniform and after filtration for oil having service life of five years. The mean value of the breakdown voltage for the oil aging naturally for five years is $40.5 \mathrm{kV}$, but in case of non - uniform field, it is $37 \mathrm{kV}$, the filtration increases the breakdown 
voltage to $45.95 \mathrm{kV}$, i.e. the breakdown voltage is increased by $14 \%$ after filtration. The breakdown voltages of transformer oil used for 10 years under uniform field, non-uniform field and uniform field after filtration are shown in fig. (14) the aged oil for 5 years but, the mean value of the breakdown voltage for aged oil (the life time equals 10 years) under uniform field is $36.7 \mathrm{kV}$, the breakdown voltage after filtration equals to $42.8 \mathrm{kV}$, i.e. The breakdown voltage after filtration is increased by approximately $20 \%$. This may be explained as filtration removes some particulate impurities, moisture and filtration render the oil more homogenous.

Fig. (14) Also, presents the breakdown voltage of transformer oil in case of uniform, non - uniform and breakdown voltage after filtration. The tested oil aging is 20 years. The filtration increases the breakdown voltage by $37 \%$. It can be seen from fig. (14) which show also, the breakdown voltage of oil sample aged 25 years that the breakdown voltage is low in both uniform and non- uniform fields because the increase of the degree of aging causes transformer oil to contain some impurity particles and particles grow in size and decrease the breakdown strength according to suspended particle theory for oil breakdown ${ }^{[11]}$. The mean value of the breakdown voltage for aged oil after 25 years in service equals $21.7 \mathrm{kV}$, which increased to $33.5 \mathrm{kV}$ after filtration. When the transformer oil reached 32 years in service, the breakdown voltage is decreased to $17.3 \mathrm{kV}$ in its mean value. However, the filtered oil breakdown voltage increased by $57 \%$.as show in fig. (14).

\section{Conclusions}

Based on the above discussions, it can be concluded that:

1. The lifetime of naturally aged transformer oil could be determined by knowing the conduction current under fixed applied voltage. This could be done by recording the conduction current of naturally aged transformer oil under different applied voltages. A lifetime equation is developed in terms of conduction current as a function of applied voltage for naturally aged oil.

2. The conduction current in $(\mu \mathrm{A})$ is measured as a function of applied voltage $(\mathrm{kV})$ for different service periods of the aged oils. The relations between the applied voltage and conduction current are plotted for different aged oils. These plots are apparently straight lines depending on the degree of oil aging. The oil of lifetime of 5 years and 10 years in service has proved to generate positive conduction currents. Those currents are, however, higher than for fresh oil. The oil samples of lifetime of 20,25 and 32 years in service has proved to generate negative conduction currents and the slopes of the curves increase with the degree 
of oil aging. Lifetime of transformer oil, as measured by the conduction current, serve as a good aging index.

\section{References}

[1] Abdel-Salam, M., Anis, H., El-Morshedy, A., and Radwan, R.; "High Voltage Engineering Theory and practice". Marcel Dekker Inc., New York, Second Edition (2000).

[2] Krins, M., Borsi, H., and Gockenbach, E.; "Impact of different water contents on the electrical strength of oil gaps and solid/liquid interfaces in the presence of carbon T5 articles", (ICDL '99). Proceedings of the 1999 IEEE $13^{\text {th }}$ International Conference on Dielectric Liquids, pp. 281-285, (1999).

[3] Kedzia, J. " Electrostatic Properties of Aged Transformer Oil", IEEE Transactions on Electrical Insulation, Vol.24, No.2, April (1989).

[4] El-refaie, E. M. and Kamal, M. "Investigations on Dielectric Strength of Transformer Oil", MEPCON' 2001, University of Helwan, Cairo, Egypt, pp.421424, December 29-31, (2001).

[5] Sarathi, R. et al. Fourth Workshop \& Conference on EHV Technology, US, Bangalore, India, (1998).

[6] Krasucki, Z.,"Higl2/15/2016h Field Conduction Processes in Dielectric Liquids", Grenoble, p.311, (1998).

[7] T.V.Ommen, 'Static Electrification Properties of Transformer Oil", special session on flow Electrification Effects in Electric Power Apparatus at the Conference on Electrical Insulation and Dielectric Phenomena, IEEE No.86, pp.206-216, (1989).

[8] Kedzia, J . "The effect of temperature on the electrification of transformer Oil in the Rotating Cylinder System", ZN WSI, Opole, 133, z 31, pp.29-36, (1987).

[9] Kedzia, J. and Brozostek, E. "Static Electrification in Transformer Oil as a Measure of Its Aging", IEEE Transactions on Electrical Insulation Vol.EI-19, No.2, April (1984).

[10] Crofts, D. W. "The static electrification phenomena in power transformer". Annual Report Conference on Electrical Insulation and Dielectric Phenomena, Claymont, pp.222- 235, (1986).

[11] Nadiu, M. S. and Kamaraju, V. "High Voltage Engineering" TATA MCGRAWHILL Publishing company limited, (1982). 


\section{درلسة معملية لتحديد عمر زيوت المحولات المقادمةطبيعيًا}

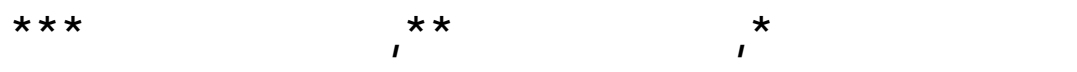

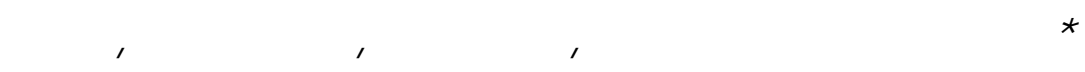

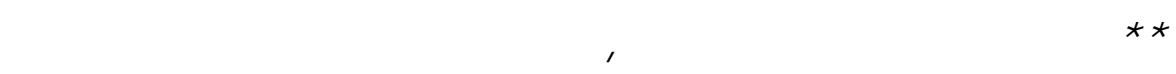

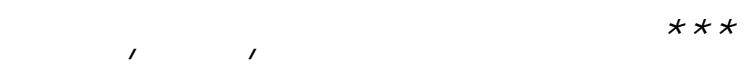

المستخلص: يتناول البهث درلمة معملية لتحديد عمر زيوت

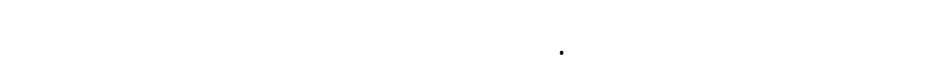

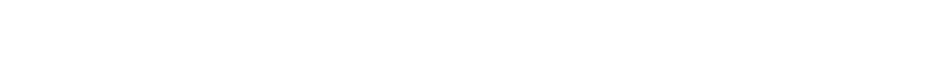

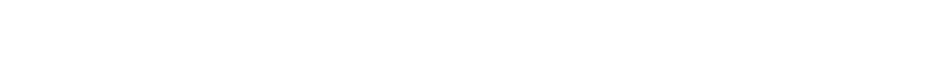

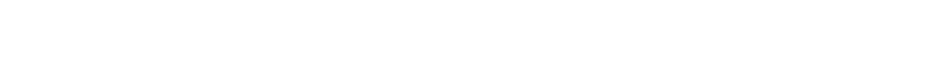

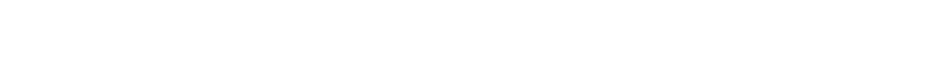

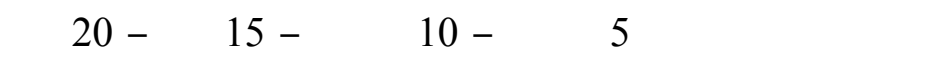

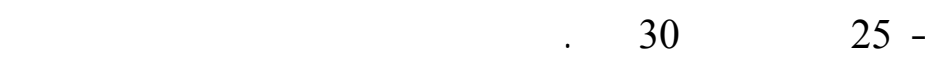
زياة ششة عزل الزيوت. وتناول البهث أيضًا دريلسة تيار التكهرب

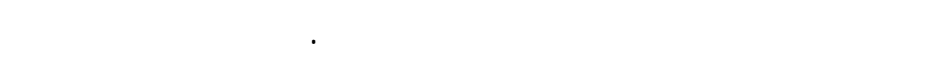

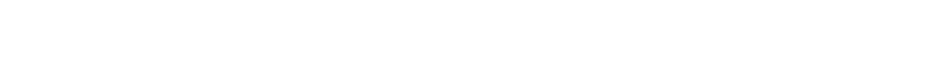

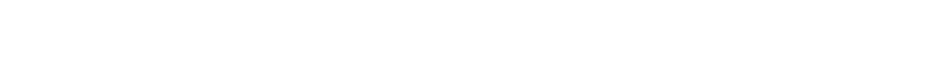

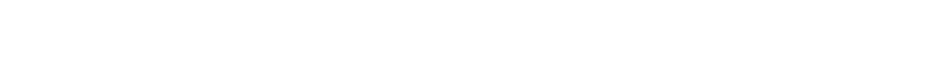

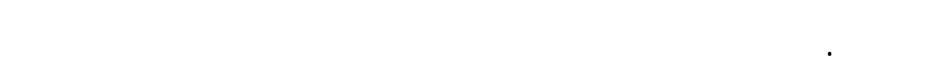
زيوت المحولات وقهم البحث عسيرًا علميًا لذك. لك. 